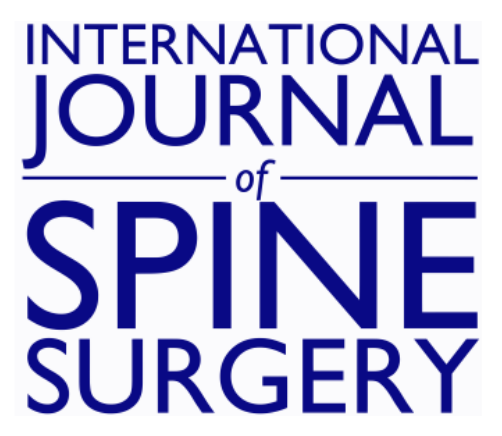

\title{
Lumbar Disc Replacement for Junctional Decompensation After Fusion Surgery: Clinical and Radiological Outcome at an Average Follow-Up of 33 Months
}

Ulrich R. Hähnle, Karen Sliwa, Ian R. Weinberg, Barry MBE Sweet, Malan de Villiers and Geoffrey P. Candy

Int J Spine Surg 2007, 1 (3) 85-92

doi: https://doi.org/10.1016/SASJ-2007-0006-RR

http://ijssurgery.com/content/1/3/85

This information is current as of April 26, 2023.

Email Alerts Receive free email-alerts when new articles cite this article. Sign up at: http://ijssurgery.com/alerts 


\title{
Lumbar Disc Replacement for Junctional Decompensation After Fusion Surgery: Clinical and Radiological Outcome at an Average Follow-Up of 33 Months
}

\author{
Ulrich R. Hähnle, MD, FCS (Ortho), Karen Sliwa, MD, PhD, Ian R. Weinberg, MD, FCS (Neuro), \\ Barry MBE Sweet, MD, PhD, Malan de Villiers, PhD, and Geoffrey P. Candy, PhD
}

\begin{abstract}
Background

Failed fusion surgery remains difficult to treat. Few published data on disc replacement surgery after failed fusion procedures exist. Our objective was to evaluate outcomes of junctional lumbar disc replacement after previous fusion surgery and to correlate outcome with radiological changes to parameters of sagittal balance.
\end{abstract}

\begin{abstract}
Methods
Out of a single-center prospective registry of 290 patients with 404 lumbar disc replacements, 27 patients had had a previous lumbar fusion operation on 1 to 4 lumbar segments and had completed a mean followup of 33 months (range: 18-56). We correlated the clinical outcome measures (patient satisfaction, 10point pain score, and Oswestry Disability Index [ODI] score) to parameters of spinal sagittal alignment (sacral tilt, pelvic tilt, pelvic incidence, and lumbar lordosis).
\end{abstract}

\begin{abstract}
Results
Postoperative hospital stay averaged 3.3 days (range: $2-8$ ). Previously-employed patients went back to their jobs with a mean of 32 days (range: 21-42) after the procedure. At the latest follow-up, 1 of the patients considered the outcome to be poor, 3 fair, 8 good, and 15 excellent. Twenty-four patients "would undergo the operation again." Average pain score decreased from $9.1 \pm 1.0(\mathrm{SD})$ to $3.2 \pm 2.1(P<.01)$. Average ODI decreased from $50.2 \pm 9.9$ preoperatively to $21.7 \pm 14.2(P \leq .01)$. We found the change in pelvic tilt to be an independent predictor of better clinical outcome by multivariate analysis $(P<.05)$.

Conclusions

In patients with junctional failure adjacent to a previous posterolateral fusion, disc replacement at the junctional level(s), compared with osteotomy and fusion surgery, offers the advantage of maintaining segmental mobility and correcting the flat-back deformity through a single approach with less operative time and blood loss. Early- to intermediate-term results are promising. The influence of changes in spinal sagittal alignment on clinical outcome needs to be addressed in future research.
\end{abstract}

Clinical Relevance

This is the first study on "junctional disc replacement patients" correlating clinical outcome to changes in spinal/pelvic alignment.

Key Words Lumbar disc replacement, junctional disc replacement, spinal alignment. SAS Journal. Summer 2007;1:85-92. DOI: SASJ-2007-0006-RR

\section{INTRODUCTION}

Failed fusion surgery patients are difficult to treat. Adjacent disc decompensation with spinal stenosis and pain at the junctional levels are known sequelae after fusion surgery. ${ }^{1-3}$ Although the association is not universally accepted, ${ }^{4}$ previous fusion and lumbar flat-back deformity seem to contribute to low-back pain and accelerated wear of the adjacent motion segments. ${ }^{1,3,5-7}$ Symptoms arising from loss of sagittal spinal alignment after previous fusion surgery remain therapeutically challenging, and long-term treatment results are satisfactory at best..$^{8-12}$ Because of the associated lumbar spinal flat-back deformity, extensive surgery with combined dorsal-ventral-dorsal, ventral-dorsal, or posterior osteotomy approaches, including an extension of the fusion, are usually applied as salvage procedures for these patients. ${ }^{10-12}$ These procedures entail long surgery time with extensive blood loss and dangers to the spinal canal and nerve roots. Artificial disc replacement in this patient group offers a promising alternative to extensive 
refusion surgery with the theoretical advantage of absorbing some of the junctional stresses.

Fernstrom ${ }^{13}$ first published in 1966 on the surgical insertion of steel balls as nucleus prostheses, but lumbar disc replacement with a modern articulating disc only began in 1984 with the first implantation of the Charite SB I prosthesis performed by Büttner-Janz. ${ }^{14}$ Since then, other more easily implantable discs have been developed (Charité SB III, DePuy Spine, Raynham, Massachusetts; ProDisc, Synthes Spine, West Chester, Pennsylvania; Maverick, Medtronic Sofamor Danek, Memphis, Tennessee; FlexiCore, Stryker Spine, Allendale, New Jersey; Kineflex, SpinalMotion, Mountain View, California). The indications and contraindications for artificial disc replacement remain controversial ${ }^{15-17}$ despite more than 10 years of followup results. ${ }^{18-20}$

Detailed correlations between clinical outcome and changes in pelvic/spinal parameters have not been reported after lumbar total disc replacement. Although previous publications on radiological sagittal alignment changes after total disc replacement did not show significant changes in pelvic alignment parameters such as pelvic incidence (PI), pelvic tilt (PT), and sacral tilt (ST), ${ }^{21,22}$ segmental lumbar lordosis (LL) at the replaced level has changed significantly. ${ }^{21-23}$ Overall LL changed in 1 study ${ }^{22}$ but not in others. ${ }^{21,23}$ No findings of a correlation between clinical outcome and changes in pelvic/spinal parameters after total disc replacement have been published, nor have results regarding the influence of juxtafusional lumbar disc prostheses on the parameters of sagittal alignment.

The aim of our study was to determine the outcomes, pitfalls, and limitations of lumbar disc arthroplasty adjacent to an existing lumbar fusion. We looked at clinical outcome parameters such as surgery time, blood loss, complications, return-to-work time and ratio, patient satisfaction, pain score, Oswestry Disability Index (ODI) score, and reoperations. We also performed radiological outcome studies, looking at parameters of sagittal spinal alignment (pelvic incidence, PT, ST, and LL). We further correlated these radiological parameters to clinical outcome parameters.

\section{MATERIALS AND METHODS}

Out of an ongoing, longitudinal, single-center prospective study involving 290 patients to date, 27 patients had had a previous posterolateral lumbar fusion operation of 1 to 4 lumbar segments and a minimum follow-up of 18 months. As the index procedure, all patients received either a Charité or a Kineflex lumbar disc replacement adjacent to the previous instrumented fusions.

The primary clinical outcome measures for this study were pain relief and functional improvement as assessed by the ODI and our own questionnaire. Patients completed questionnaires preoperatively and at 6 weeks, 3 months, 6 months, and yearly thereafter in conjunction with the regular follow-up examinations. In addition to the outcome data, we collected general demographic information and operative data as well as data pertaining to radiological examination.

Inclusion criteria for the study were (1) previous lumbar fusion operation, (2) age of 18 to 65 years, and (3) symptomatic adjacent single- or double-level disc disease of the lumbar spine below the L1-L2 level confirmed on X-rays, magnetic resonance imaging, or computer tomography-myelography imaging. We performed preoperative discography only in cases when, after clinical examination and radiographic evaluation, doubt persisted about inclusion or exclusion of a lumbar level in the operation. We performed diagnostic facet joint infiltrations when junctional low-back pain was a significant symptom. Diagnostic (and therapeutic) sacroiliac joint injections were performed in most cases. Further inclusion criteria were mechanical back or leg pain, broad-based central disc herniation without sequestration, or sequestration in line with the disc space. All patients had failed supervised conservative treatment of at least 3 months, except for one patient who presented with progressive neurological deficits. Only the symptomatic levels on clinical examination and/or discography were replaced.

Exclusion criteria for junctional disc replacement were osteoporosis, tumor, infection, spondylolysis of the relevant level, bony spinal stenosis, sequestrated disc prolapse tracking up or down behind the vertebral body, morbid obesity (BMI $\geq$ 40), previous retroperitoneal surgery, vascular pathology, and previous wide laminectomy with destabilization of the facet complex. Advanced facet arthritis was not an exclusion criterion unless osteophyte formation from the facet resulted in bony canal or recess stenosis. Spinal or lateral recess stenosis caused by soft tissue (disc, ligamentum flavum, or facet joint capsule) was not a contraindication for disc replacement if proper decompression during surgery, by means of direct or indirect decompression, could be anticipated on preoperative imaging.

Two of the authors (Hähnle and Weinberg) designed our questionnaire; it has not been validated. The patients were asked about satisfaction with the outcome of the treatment operation (excellent, good, fair, or poor). The patients were asked whether they would undergo the same operation again or recommend it to friends (yes, no, don't know) and to gauge their pain at the time of completing the questionnaire on a scale of 1 (no pain) to 10 (pain as bad as it can be).

\section{Clinical Evaluation}

During clinical examinations, the patients physically had to indicate painful areas of the back and lower limbs. This was followed by palpation of the interspinous spaces in both standing and prone positions to determine the levels associated with pain. Routine spinal examinations followed.

\section{Radiographic Evaluation}

All patients had a preoperative magnetic resonance imaging or lumbar myelography followed by computer tomography. 
Preoperatively and at 3 months, 6 months, and annually postoperative, we took anteroposterior and lateral standing radiographs, which included the bottom endplate of the T12 vertebra and the top half of both femoral heads. We also took a lateral whole spine standing radiograph. The patients were asked to stand straight with the arms crossed over the chest and knees fully extended. These follow-ups also included lateral flexion/extension radiographs. We based the spinal balance evaluation on the studies of Duval-Beaupere et al. ${ }^{24-26}$ and Lazennec et al. ${ }^{6}$ (Figure 1). We looked at pelvic incidence, ST, PT, LL (cephalad endplate L1-cephalad endplate S1), and segmental LL, which is the angle between the cephalad endplate of the level of the total disc replacement (TDR) to cephalad endplate S1 (TDR-S1) (or other reproducible marker within the fusion mass). If the femoral heads were not exactly superimposed on each other, the middle of the line connecting the centers of the femoral heads was used to determine the PI and PT. We correlated the clinical outcome of our patients with the radiological changes in spinal balance parameters.

\section{Figure 1}

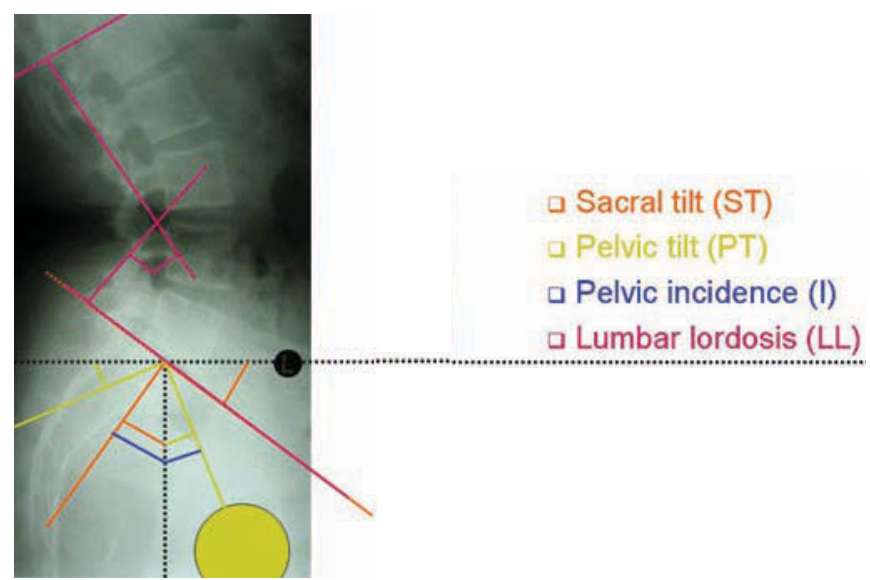

Note. Yellow circle $=$ hip joint; horizontal and vertical dotted lines cross the middle of the $\mathrm{S} 1$ endplate. Black circle was a label on the original X-ray.

Lumbar and pelvic spinal alignment measurements.

\section{Operative Technique}

We performed all operations on a translucent electrical table under radiographic image control with intraoperative cellsaving in all patients. A mini-retroperitoneal approach through a midline incision was used. After a midline annuloplasty, we removed the disc nucleus, the inner layer of the annulus, any sequestrated disc material, and posterolateral osteophytes. We prepared the endplates with curettes before sequential distraction of the disc space with wedge distracters of increasing size. The insertion technique was dependent on the implant used.

\section{Postoperative Mobilization}

Patients were allowed to ambulate the day after surgery without bracing. Patients restarted supervised gait training, isometric muscle strengthening, and stretching exercises from the first postoperative day. At discharge, patients were instructed to walk every day and to continue with isometric muscular exercises and stretching exercises, and they were allowed to sit as long as they felt comfortable. Cycling on a stationary bike was encouraged after removal of stitches at 12 days postoperation. Other nonimpact sports were allowed at 6 weeks and impact sports at 4 months.

All employed office workers were allowed to return to work after 4 weeks provided they could sit for prolonged periods without additional discomfort. Manual workers were kept off work for 6 weeks postsurgery and were then allowed to go back on light duty (no lifting of more than $10 \mathrm{~kg}$, no vibration, only limited bending, and no running) for the next 6 weeks. Self-employed patients were allowed to return to work at their discretion, provided it would not result in additional discomfort.

\section{STATISTICAL METHODS}

Data were reported as mean \pm SD with SAS 9.1 (SAS Institute Inc, Cary, North Carolina) for statistical analysis and comparisons. We compared changes in measured variables pre- and postoperation with a nonparametric Wilcoxon signed rank test $(P<.05)$. We used regression analysis to determine variables that significantly influenced outcome, including pain.

\section{RESULTS}

Clinical Outcome

Table 1 summarizes the baseline data of our patients. The average age of the 27 patients was 49.2 years (range, 33-63 years). Thirteen patients were female. All patients presented with low-back pain over the lumbosacral junction radiating into 1 or both sacroiliac joints and buttocks. Twenty-four of the 27 patients presented with symptoms of spinal stenosis.

Seven patients underwent a junctional disc replacement with a Charite lumbar disc prosthesis and 20 patients with a Kineflex lumbar disc prosthesis. In 4 patients, a second-level disc prosthesis was inserted. An additional osteotomy (OT) and anterior or posterior fusion were performed during the index procedure in 4 patients (the OT group) to help with correction of the flatback deformities.

The average follow-up period lasted 32.9 months (range, 18-56). Successful outcome was achieved in $85 \%$ of the patients by the last follow-up (15 of the patients considered the outcome to be excellent, 8 good, 3 fair, and 1 poor) (Figure 2a). Twentyfour patients stated they "would undergo the operation again," 2 "did not know," and 1 of the patients stated that he "would not undergo the same operation again." The 10-point pain score decreased from $9.1 \pm 1.0$ preoperatively to $3.2 \pm 2.1(P<.01)$ at the latest follow-up. The ODI score decreased from $50.2 \pm 9.9$ preoperatively to $21.7 \pm 14.2(P<.01)$ (Figure $2 b)$. The sacroiliac joint symptoms and the spinal stenosis symptoms disappeared or significantly improved in all patients after the index procedure.

The average operation time was $134 \pm 80 \mathrm{~min}$, and the average estimated blood loss was $290 \pm 335 \mathrm{~mL}$, including the 4 patients with dorsal-ventral-dorsal and posterior osteotomy surgery at 


\section{SASJournal}

Table 1

\begin{tabular}{|c|c|}
\hline \multicolumn{2}{|c|}{ Preoperative Characteristics of Study Population $(n=27)$} \\
\hline & $\begin{array}{l}\text { No. or Mean } \\
\pm \text { SD }(n=27)\end{array}$ \\
\hline Male, no. & 14 \\
\hline Age, mean $\pm S D, y$ & $49.2 \pm 9.3$ \\
\hline Height, mean $\pm \mathrm{SD}, \mathrm{cm}$ & $171.2 \pm 8.3$ \\
\hline Weight, mean \pm SD, kg & $80.7 \pm 17.6$ \\
\hline Pain duration, mean $\pm \mathrm{SD}$, mo & $51.1 \pm 58.1$ \\
\hline \multicolumn{2}{|l|}{ Nonoperative care } \\
\hline Physiotherapy & 25 \\
\hline Chiropractic care & 15 \\
\hline Acupuncture & 7 \\
\hline \multicolumn{2}{|l|}{ Previous surgeries } \\
\hline Discectomy & 12 \\
\hline Laminectomy & 23 \\
\hline $\begin{array}{l}\text { Posterolateral } \\
\text { fusion procedures }\end{array}$ & 33 \\
\hline $\begin{array}{l}\text { Posterolateral interbody } \\
\text { fusion }\end{array}$ & 1 \\
\hline \multicolumn{2}{|l|}{ Levels fused preoperatively } \\
\hline 1 & 18 \\
\hline 2 & 8 \\
\hline 3 & 0 \\
\hline 4 & 1 \\
\hline Smokers & 13 \\
\hline \multicolumn{2}{|l|}{ Preoperative employment status } \\
\hline Employed & 19 \\
\hline Not employed & 3 \\
\hline Disabled & 2 \\
\hline Retired & 3 \\
\hline Claim or compensation patients & 2 \\
\hline
\end{tabular}

the time of the index procedure. Postoperative hospital stay averaged 3.3 days (range, 2-8) (Table 2). All employed ( $n=$ 22) patients went back to their previous occupations an average of 32 days (range, 21-42) after the procedure. Four patients required subsequent reoperations (Table 3) (Figure 3).

\section{Radiological Changes to Sagittal Alignment and Correlation with Clinical Outcome}

From before the surgery to the latest follow-up, overall LL (L1S1 level) increased by $10.4^{\circ}$ for all patients and by $18.25^{\circ}$ in the 4 patients with additional osteotomies (OT group); the segmental lordosis (TDR-S1) increased by $9.8^{\circ}$. The pelvic incidence remained unchanged. The ST increased by $5^{\circ}\left(4.25^{\circ}\right.$ in the OT group), and the pelvic tilt decreased by $5^{\circ}$ (Figure 4$)\left(3.5^{\circ}\right.$ in the OT group).

Patients' outcome was correlated with the postoperative change of LL, ST (Figure 5), and PT (Figure 6) with univariate and multivariate analysis. Only the change in PT was found to be an
Figure 2
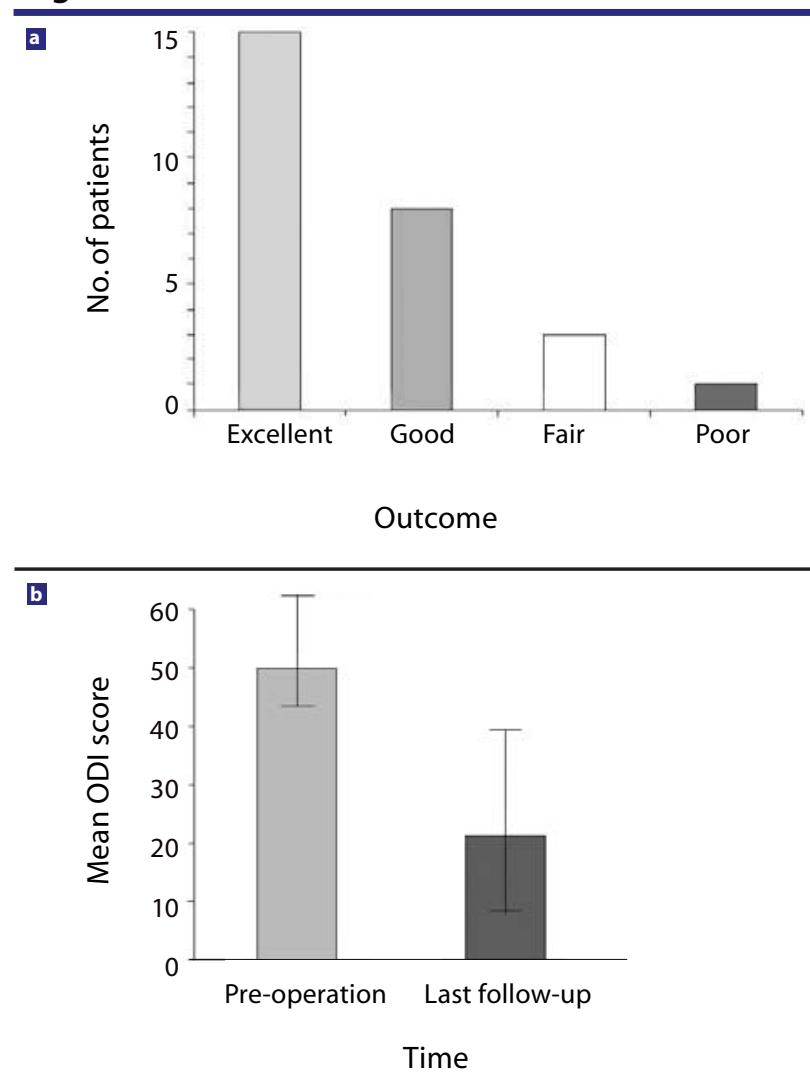

Clinical outcome at last follow-up (average 33 months, range 18-56 months, $n=27$ ): (a) patient's satisfaction with the clinical outcome; (b) Oswestry Disability Index (ODI) (1-100) score.

Table 2

\begin{tabular}{ll}
\hline Mean Operative Time, Blood Loss, and Length of Hospital Stay $(n=27)$ \\
\hline & Mean \pm SD \\
\hline Operative time, all patients, min & $134 \pm 80$ \\
Estimated blood loss, $\mathrm{mL}$ & $290 \pm 335$ \\
Dorsal-ventral-dorsal surgery/OT surgery, no. $(n=27)$ & 4 \\
Hospital stay, all patients, days & $3.3(1.1)$ \\
\hline Note. OT = osteotomy.
\end{tabular}

independent predictor for improved clinical outcome in multivariate analysis after adjusting for age, sex, height, and weight $(P<.05)$. Correlation for ST was statistically significant in the univariate $(P<.05)$ analysis but just missed statistical significance in the multivariate analysis $(P<.08)$. No correlations were found between clinical outcome and the increase or preoperative value of lumbar lordosis angles or the preoperative values of pelvic incidence.

\section{DISCUSSION}

We present our experience of lumbar disc replacement for junctional decompensation after previous fusion surgery. Similar to the outcome of the only larger series, published by Bertagnoli et al., ${ }^{27}$ in our series of 27 patients, good outcome was achieved in $85 \%$ 
Table 3

\begin{tabular}{|c|c|c|}
\hline \multicolumn{3}{|l|}{ Revision Surgeries } \\
\hline $\begin{array}{l}\text { Time After Index } \\
\text { Surgery }\end{array}$ & Problem & Treatment Applied \\
\hline Patient $1: 2$ days & $\begin{array}{l}\text { Incomplete recess } \\
\text { decompression }\end{array}$ & $\begin{array}{l}\text { Removal of prosthesis, de- } \\
\text { compression, reinsertion } \\
\text { of same prosthesis }\end{array}$ \\
\hline Patient 2: 10 mo & $\begin{array}{l}\text { Recurrent mechanical } \\
\text { stenosis symptoms } \\
\text { because of persistent } \\
\text { flat back after disc } \\
\text { prosthesis at L3-L4 }\end{array}$ & $\begin{array}{l}\text { Disc replacement } \mathrm{L} 5-\mathrm{S} 1+ \\
\text { anterior cage at posterior } \\
\text { fused } \mathrm{L} 4-\mathrm{L} 5\end{array}$ \\
\hline \multirow[t]{2}{*}{ Patient 3: 26 mo } & $\begin{array}{l}\text { Recurrent mechanical } \\
\text { stenosis symptoms } \\
\text { because of persistent } \\
\text { flat back after disc } \\
\text { prosthesis at L3-L4 }\end{array}$ & $\begin{array}{l}\text { Double posterior osteoto- } \\
\text { my (OT) (pedicle substrac- } \\
\text { tion OT L5 and multiple, } \\
\text { limited OTs T9-L1) }\end{array}$ \\
\hline & $\begin{array}{l}\text { Additional thoracic } \\
\text { kyphosis of } 74^{\circ}\end{array}$ & See Figure 3 \\
\hline Patient 4:41 mo & $\begin{array}{l}\text { Persistent flat-back } \\
\text { deformity and pro- } \\
\text { gressive instability at } \\
\text { disc level with sciatica } \\
\text { and low-back pain }\end{array}$ & $\begin{array}{l}\text { Exchange prosthesis } \\
\text { L4-L5 for higher-angled } \\
\text { prosthesis of different } \\
\text { make }\end{array}$ \\
\hline
\end{tabular}

increased and the pelvic incidence stayed the same in all patients at follow-up. A stronger postoperative increase in ST and decrease in PT correlated with better clinical outcome. This result was not produced by the inclusion of the 4 patients with an additional OT (OT group), as the patients in the OT group had similar or lesser changes in their ST and PT. Lazennec et al. $^{6}$ found that in 81 patients who had undergone lumbosacral fusion, PT was significantly higher and ST significantly lower in patients with postfusion pain. No published results are available for patients after juxtafusional disc replacement.

Le Huec et al. ${ }^{21}$ measured, preoperatively and postoperatively, parameters of sagittal spinal balance after total disc arthroplasty. $\mathrm{He}$ and others ${ }^{22}$ found no significant changes in pelvic alignment parameters (ST and PT). The segmental lordosis increased at the level of the disc replacement, ${ }^{21-23}$ but only Chung et al. ${ }^{22}$ found a significant increase of the overall LL. Patients undergoing isolated single-level disc replacement are unlikely to present with a significant preoperative sagittal spinal imbalance. Patients undergoing disc replacement after a previous posterolateral fusion, as opposed to patients with

\section{Figure 3}

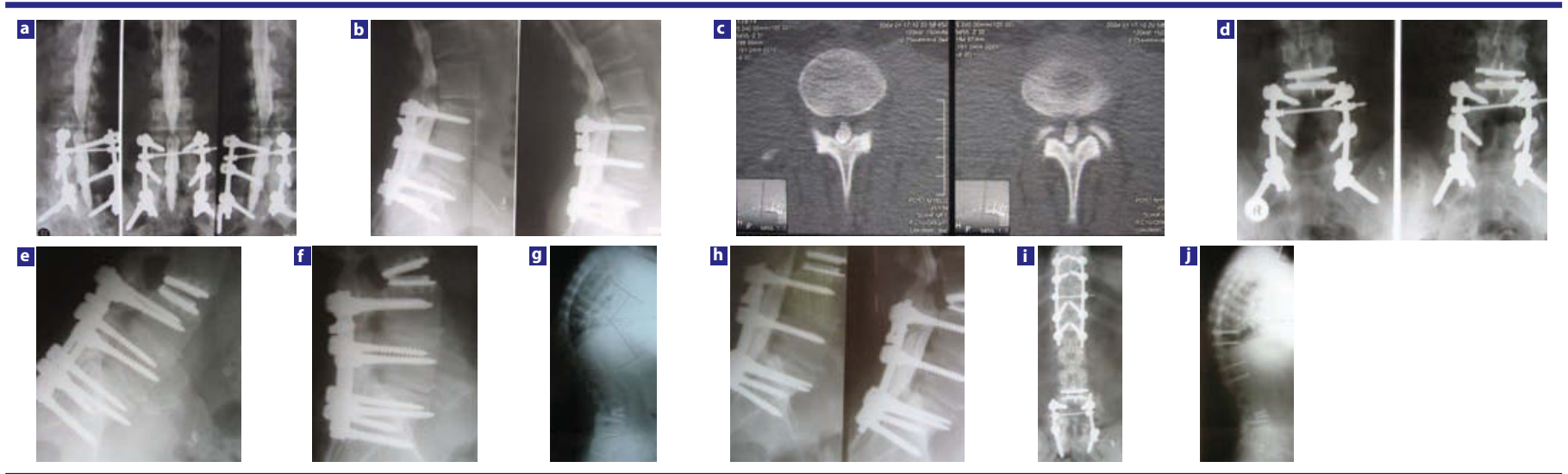

A case study demonstrating the limitations of a single-disc replacement in correcting a spinal flat-back deformity: (a-c) a 45-year-old obese male patient underwent posterolateral fusion in 1998 and had significant mechanical back and leg pain thereafter; he presented with bilateral foot drop and severe low-back pain 5 years later; $(\mathrm{d}-\mathrm{g})$ after junctional disc replacement the patient was doing well during follow-up until 2 years after the index surgery; $(\mathrm{h})$ at 26 months post-index surgery the patient re-presented with spinal stenosis, a rightsided foot drop, and severe low-back pain; radiographs showed extended disc prosthesis and myelography confirmed spinal stenosis behind disc prosthesis; $(i, j)$ after double osteotomy (OT) (pedicle substraction OT L5 and multiple lower thoracic OTs as well as a direct posterior decompression L3-L4), rebalancing of the prosthetic disc and complete relief from symptoms.

of the patients by the mean follow-up of 33 months. During the follow-up period, 4 patients underwent further surgery (Table 3 ).

We used 2 different unconstrained disc prostheses: the Charité SBIII prosthesis in the first 7 patients and the Kineflex lumbar disc prosthesis in the last 20 patients. Because of the small number of patients in the former group, a statistically meaningful comparison between the 2 groups was not feasible.

We further analyzed parameters of sagittal spinal alignment in our juxtafusional disc replacement patient group and correlated these parameters to clinical outcome. The pelvic incidence of our patient group was similar to normal values. ${ }^{26}$ The LL previous anterior lumbar interbody fusion or 360-degree fusions, in most instances present with a lumbar flat-back deformity because of incomplete anterior column height restoration. The disc prosthesis then allows the possibility of correcting the sagittal deformity in part or in its entirety.

Four patients underwent reoperations during the follow-up period (Table 3). Except for 1 patient who had an inadequate recess decompression during the index procedure, the remaining 3 patients, after temporary relief of their symptoms, experienced recurring symptoms of spinal stenosis and lumbosacral pain with the disc prosthesis in an extended position on lateral standing radiographs. Two of these patients had an increased 
Figure 4

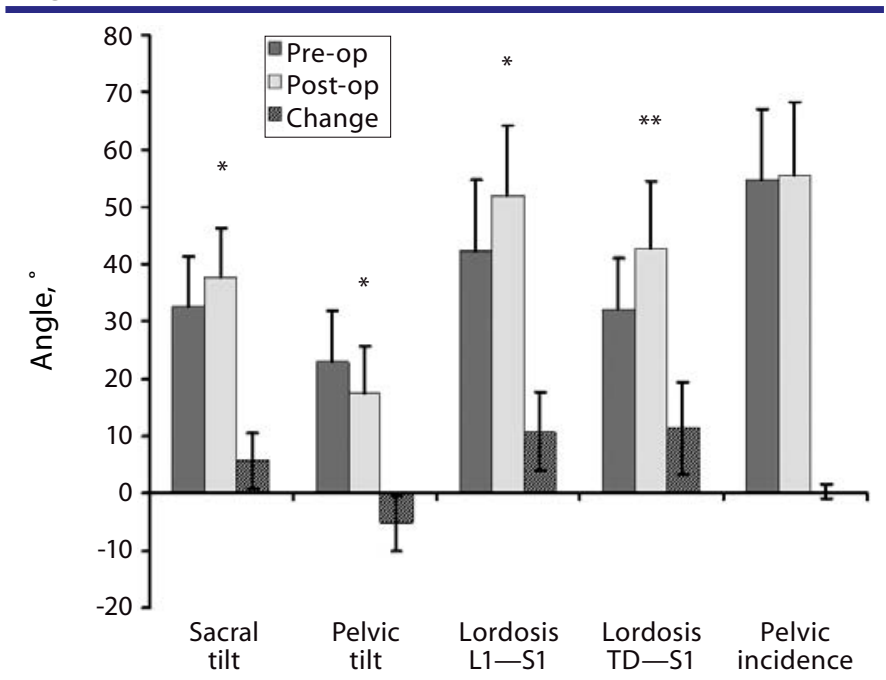

Overall changes in measured parameters

Note. TD $=$ total disc. ${ }^{*} P<.05 ;{ }^{* *} P<.01$.

Lumbar and pelvic parameters determined preoperatively and at latest follow-up.

preoperative thoracic kyphosis, between $40^{\circ}$ and $60^{\circ}$ on lateral standing radiographs, both of which increased in later followup by more than $10^{\circ}$ in the thoracolumbar junction area. The index level was significantly extended and in retrolisthesis on preoperative lateral standing radiographs in all 3 patients, the next cranial level in 2 of the patients. We therefore would consider osteotomy surgery or additional OT surgery for patients presenting with these radiological features. After reoperation, their PT decreased and ST increased significantly (not included in our calculations).

Treating "failed fusion surgery patients" requires consideration of the high rates of clinical complication and revision and of suboptimal results in patient satisfaction. ${ }^{10,11,28-30}$ Extensive procedures are often required, incorporating combined anterior and posterior spinal surgery or posterior extension osteotomies with extension of the fusion surgery. ${ }^{10-12,29,30}$

To date, the authors have placed disc prostheses in 34 patients after previous lumbar fusion surgery and are generally impressed with the speed and extent of recovery as well as the satisfaction of these patients with the operation. We are aware of 3 publications on juxtafusional disc replacement. ${ }^{27,31,32}$ The disc used by Enker et al. ${ }^{31}$ consisted of an elastic rubber core interposed between 2 titanium endplates and was only used in 4 patients with junctional disc degeneration. Because of prosthetic failure it has long been withdrawn from the market. The study by Kim et al. ${ }^{32}$ reflects the outcome of 5 patients with only 6 months of follow-up. Only Bertagnoli et al. ${ }^{27}$ has published a larger series of patients with juxtafusional disc replacement and 2 years of follow-up with excellent clinical outcome. None of

\section{Figure 5}
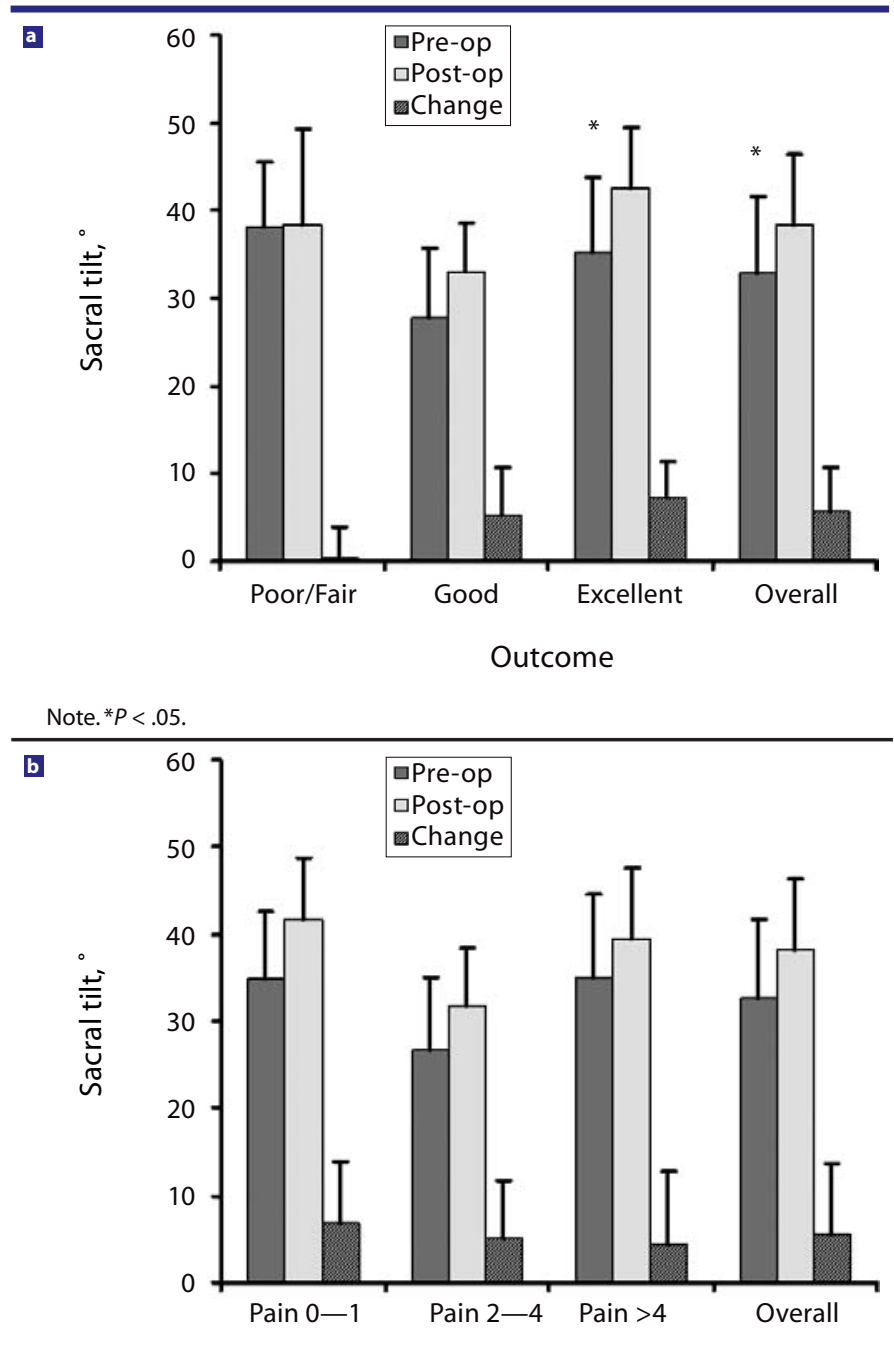

Outcome

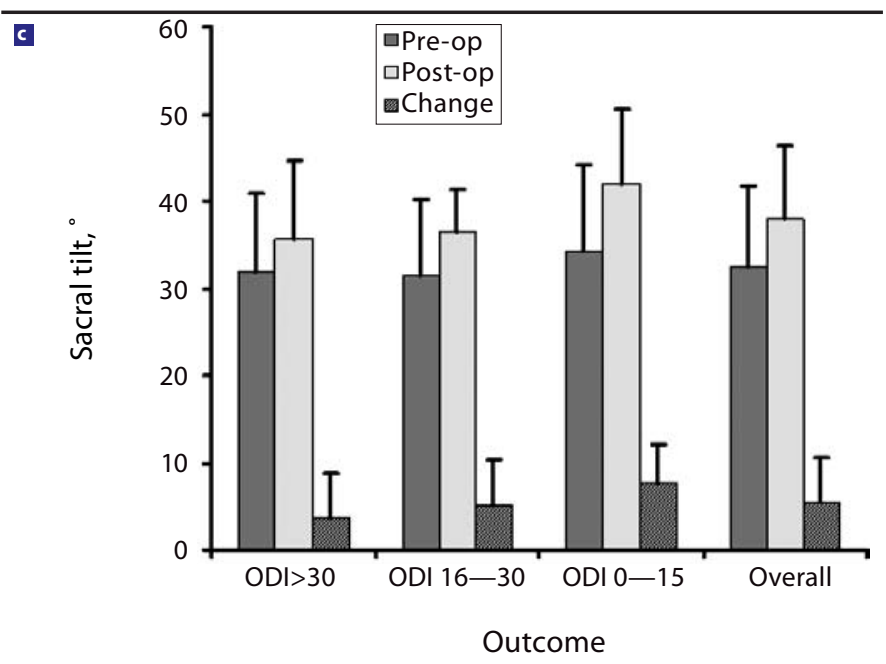

Changes in sacral tilt in relation to clinical outcome: (a) sacral tilt and satisfaction with surgical outcome; (b) sacral tilt and pain score; (c) sacral tilt and Oswestry Disability Index (1-100) score. 


\section{Figure 6}

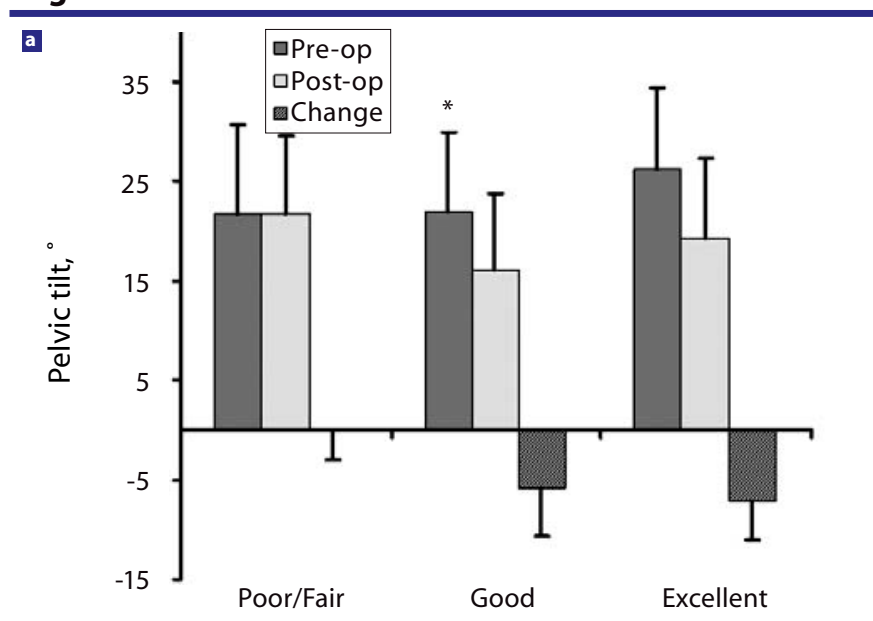

Outcome
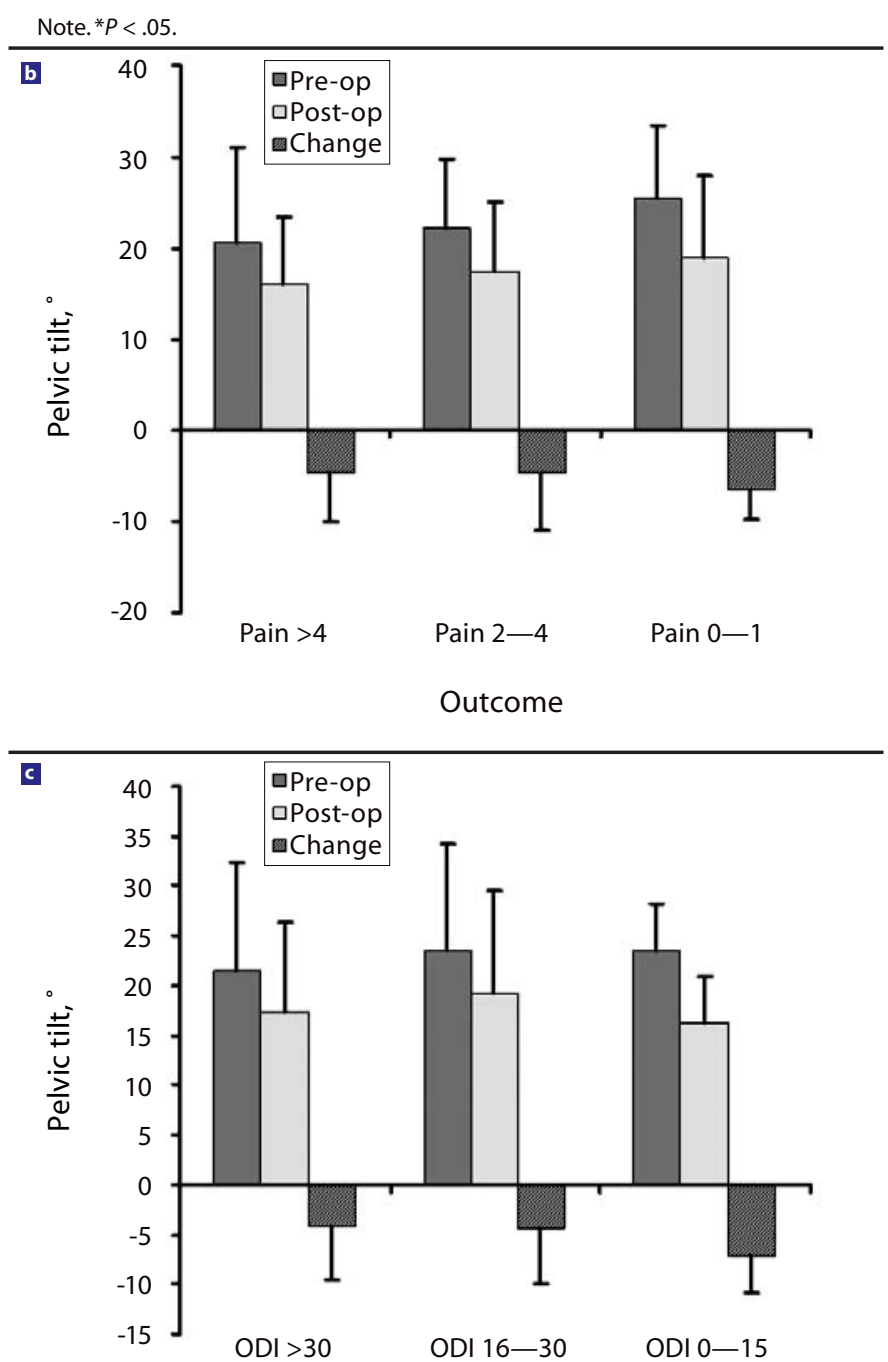

Outcome

Changes in sacral tilt in correlation to clinical outcome: (a) pelvic tilt and satisfaction with surgical outcome; (b) pelvic tilt and pain score; (c) pelvic tilt and Oswestry Disability Index (ODI) (1-100) score. the publications comments on the changes of parameters of spinal and pelvic alignment in this patient group.

Most patients with previous posterolateral fusion surgery present with a lumbar flat-back deformity. Unless the sagittal balance is fully restored during prosthetic disc surgery, the replaced disc prosthesis would rebalance itself into an extended position with the upright standing patient. This can lead to excessive facet joint loading as well as continuous or recurrent spinal and recess stenosis symptoms caused by bulging of the posterior soft tissue structures into the spinal canal and closing of the foraminal exits in an extended position of the lumbar segment. In 3 of our 4 reoperation patients, the further surgeries were performed for this reason (Table 3).

It is our opinion that posterior placement of the prosthesis within the disc space, placement of a taller disc prosthesis, and the use of wedged endplates can correct the flat back only in patients with minor deformities. An additional osteotomy through the fusion mass should be considered in more severe sagittal imbalance. Whole-spine lateral standing radiographs should be used to asses the sagittal balance in all juxtafusion disc replacement patients preoperatively and at follow-up. As a working hypothesis we consider the following radiological parameters as risk factors for later decompensation and future clinical failure: a retroverted pelvis with increased pelvic tilt; an overextended disc or disc prosthesis with or without retrolisthesis at the index level and the more cranial lumbar levels; a hypermobile index level; and thoracic kyphosis, especially low in the thoracolumbar junction area.

Patients with junctional failure adjacent to a previous posterolateral fusion are a therapeutic challenge. Junctional disc replacement appears to be a good procedure after juxtafusional failure, provided a good sagittal balance is present or is restored during replacement surgery. Longer follow-up will be needed. There is a clear need for other investigators to report on their results with these patients.

Ulrich R. Hähnle, MD, FCS (Ortho); Karen Sliwa, MD, PhD; Ian R. Weinberg MD, FCS (Neuro); Barry MBE Sweet, MD, PhD; Malan de Villiers, PhD, and Geoffrey P. Candy, PhD

From the Department of Orthopedic Surgery, University of the Witwatersrand, Johannesburg, South Africa (Hähnle and Sweet); Linksfield Park Clinic, Johannesburg (Hähnle and Weinberg); the Department of Medicine, University of the Witwatersrand (Sliwa); the Department of Mechanical Engineering, University of Potchefstrom, Potchefstrom, South Africa (de Villiers); Southern Medical, Wpadrand, South Africa (de Villiers); and the Department of Surgery, University of the Witwatersrand (Candy).

Ulrich R. Hähnle, Ian R. Weinberg, and Malan de Villiers are co-developers of the Kineflex disc and shareholders in SpinalMotion, Mountain View, California.

Address correspondence and reprint requests to Ulrich Hähnle, PO Box 52040, Saxonwold 2132, Johannesburg, South Africa (email: hahnleu@mdh-africa.org). Downloaded from http://ijssurgery.com/ by guest on April 26, 2023 
This submission was received March 29, 2007, and accepted for publication June 15, 2007.

We would like to thank Stephanie Hanekom and Aldorin Gehring for their enthusiastic support with patient management and follow-up.

The IRB of the hospital where all procedures were performed (Nedcare Linksfield Hospital, Nedcare, Johannesburg, South Africa) approved this study, which was conducted in accordance with the ethical standards of the Declaration of Helsinki (2000). Informed written consent was obtained from all patients.

\section{REFERENCES}

1. Gillet P. The fate of the adjacent motion segments after lumbar fusion. $J$ Spinal Disord Tech. 2003;16(4):338-345.

2. Kumar MN, Jacquot F, Hall H. Long-term follow-up of functional outcomes and radiographic changes of adjacent levels following lumbar spine fusion for degenerative disc disease. Eur Spine J. 2001;10:309-313.

3. Kumar MN, Baklanov A, Chopin D. Correlation between sagittal plan changes and adjacent segment degeneration following lumbar spine fusion. Eur Spine J. 2001;10:314-319.

4. Hambly MF, Wiltse LL, Raghavan N, Schneiderman G, Koenig C. The transition zone above a lumbosacral fusion. Spine. 1998;23:1785-1792.

5. Glassman SD, Bridwell K, Dimar JR, Horton W, Berven S, Schwab F. The impact of positive sagittal balance in adult spinal deformity. Spine. 2005;30:2024-2029.

6. Lazennec JY, Ramare S, Arafati N, et al. Sagittal alignment in lumbosacral fusion: relation between radiological parameters and pain. Eur Spine J. 2000;9:47-55.

7. Park P, Garton HJ, Gala VC, Hoff JT, McGillicuddy JE. Adjacent segment disease after lumbar or lumbosacral fusion: review of the literature. Spine. 2004;27:1938-1944.

8. Christensen FB, Thomsen K, Eiskjaer SP, Gelinick J, Bünger CE. Functional outcome after posterolateral spinal fusion using pedicle screws: comparison between primary and salvage procedure. Eur Spine J. 1998;7:321-327.

9. Hadjipavlou A, Enker P, Dupuis P. The cause of failure of lumbar transpedicular spinal instrumentation and fusion. Int Orthop. 1996;20:35-42.

10. Lagrone MO, Bradford DS, Moe JH et al. Treatment of symptomatic flatback after spinal fusion. J Bone Joint Surg Am. 1998;70(4):569-580.

11. Bridwell KH, Lewis SJ, Edwards C, et al. Complications and outcomes of pedicle substraction osteotomies for fixed sagittal imbalance. Spine. 2003;28:2093-2101.

12. Potter BK, Lenke LG, Kuklo TR. Prevention and management of iatrogenic flatback deformity. J Bone Joint Surg Am. 2004;86:1793-1808.

13. Fernström U. Arthroplasty with intercorporal endoprothesis in herniated disc and in painful disc. Acta Chir Scand Suppl. 1966;357:154-159.

14. Büttner-Janz K, Schellnack K, Zippel H. Eine alternative Behandlungsstrategie beim lumbalen Bandscheibenschaden mit der Bandscheiben-endoprothese Modulartyp SB Charite [An alternative treatment strategy in lumbar intervertebral disk damage using an SB Charité modular type intervertebral disk endoprosthesis]. Z Orthop Ihre Grenzgeb. 1987;125:1-6.

15. Huang R, Lim MR, Girardi FP, Cammisa FP. The prevalence of contraindications to total disc replacement in a cohort of lumbar surgical patients. Spine. 2004;29:2538-2541.
16. McAfee Paul C. The indications for lumbar and cervical disc replacement. Spine J. 2004;4(6 Suppl):177-181.

17. Wong D, Annesser B, Birney T, et al. Incidence of contraindications to total disc arthroplasty: a retrospective review of 100 consecutive fusion patients with a specific analysis of facet arthrosis. Presented at World Spine 3, July 31-August 3, 2005, in Rio de Janeiro, Brazil.

18. Lemaire JP. SB Charité III intervertebral disc prosthesis: biomechanical, clinical, and radiological correlations with a series of 100 cases over a follow-up of more than 10 years [in French]. Rachis. 2002;14(4):271-285.

19. Lemaire JP, Carrier H, Sariali el-H, Skalli W, Lavaste F. Clinical and radiological outcomes with the Charite artificial disc: a 10-year minimum follow-up [published correction appears in J Spinal Disord Tech. 2006;19(1):76]. J Spinal Disord Tech. 2005;16(4):353-359.

20. Tropiano P, Huang RC, Girardi FP et al. Lumbar total disc replacement: Seven to eleven-year follow-up. J Bone Joint Surg Am. 2005;87:490-496.

21. Le Huec JC, Basso Y, Mathews H, et al. The effect of single-level, total disc arthroplasty on sagittal balance parameters: a prospective study. Eur Spine J. 2005;14(5):480-486.

22. Chung SS, Lee CS, Kang CS, Kim SH. The effect of lumbar total disc replacement on the spinopelvic alignment and range of motion of the lumbar spine. J Spinal Disord Tech. 2006;19(5):307-311.

23. Cakir B, Richter M, Kafer W, Puhl W, Schmidt R. The impact of total lumbar disc replacement on segmental and total lumbar lordosis. Clin Biomech. 2005;20(4):357-364.

24. Duval-Beaupere G, Schmidt C, Cosson P. A Barycentremetric study of the sagittal shape of spine and pelvis: the conditions required for an economic standing position. Ann Biomed Eng. 1992;20(4):451-462.

25. Legaye J, Duval-Beaupere G, Hecquet J, Marty C. Pelvic incidence: a fundamental pelvic parameter for three-dimensional regulation of spinal sagittal curves. Eur Spine J. 1998;7(2):99-103.

26. Boulay C, Tardieu C, Hecquet J, et al. Sagittal alignment of spine and pelvis regulated by pelvic incidence: standard values and prediction of lordosis. Eur Spine J. 2006;15(4):415-422.

27. Bertagnoli R, Yue JJ, Fenk-Mayer A, Eerulkar J, Emerson JW. Treatment of symptomatic adjacent-segment degeneration after lumbar fusion with total disc arthroplasty by using the prodisc prosthesis: a prospective study with 2-year minimum follow up. J Neurosurg Spine. 2006;4(2):91-97.

28. Fritsch EW, Heisel J, Rupp S. The failed back surgery syndrome: reasons, intraoperative findings, and long-term results: a report of 182 operative treatments. Spine. 1996;21(5):626-633.

29. Slosar PJ, Reynolds JB, Schofferman J, Goldthwaite N, White AH, Keaney D. Patient satisfaction after circumferential lumbar fusion. Spine. 2000;25:722-726.

30. Stewart G, Sachs BL. Patient outcomes after reoperation on the lumbar spine. J Bone Joint Surg Am. 1996;78:706-711.

31. Enker P, Steffee A, McMillin C, Keppler L, Biscup R, Miller S. Artificial disc replacement. Preliminary report with a 3 -year minimum follow-up. Spine. 1993;18(8):1061-1070.

32. Kim WJ, Lee SH, Kim SS, Lee C. Treatment of juxtafusional degeneration with artificial disc replacement (ADR): preliminary results of an ongoing prospective study. J Spinal Disord Tech. 2003;16(4):390-397. 